\title{
Advances in imaging vascular inflammation
}

\author{
Nikil K. Rajani · Francis R. Joshi · Jason M. Tarkin • \\ James H. F. Rudd
}

Received: 13 May 2013/Accepted: 5 September 2013/Published online: 1 October 2013

(C) Italian Association of Nuclear Medicine and Molecular Imaging 2013

\begin{abstract}
Inflammation is central to the pathogenesis of many vascular diseases. Despite an understanding of the natural history, predicting progression and acute complications remains an important clinical challenge in both atherosclerosis and aortic aneurysms. Current means of monitoring rely mainly on structural information, such as the extent of luminal stenosis on coronary angiography or maximum aneurysm diameter on ultrasonography. Although often useful in making clinical decisions about intervention, such measures do not always correlate well with the risk of acute complications. As an example, the degree of luminal obstruction correlates poorly with the risk of future coronary plaque rupture and, similarly, aneurysm size does not account entirely for the subsequent rate of expansion and risk of rupture. It might be possible to improve risk prediction using imaging modalities that focus on the underlying disease processes rather than their consequences. This article reviews non-invasive imaging techniques that track inflammation within the arterial wall as applied to atherosclerosis and abdominal aneurysms. These all aim to improve risk prediction, to highlight the underlying pathology non-invasively and to permit the testing of new therapeutic agents against vascular disease.
\end{abstract}

Keywords Atherosclerosis - Aneurysm - Plaque rupture $\cdot$ Molecular imaging $\cdot$ Positron emission tomography $\cdot$ Nuclear imaging

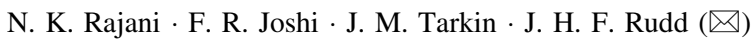
Division of Cardiovascular Medicine, University of Cambridge, Addenbrooke's Hospital, Box 110, ACCI, Hills Road, Cambridge CB2 2QQ, UK

e-mail: jhfr2@cam.ac.uk

\section{Introduction}

Atherosclerosis is a systemic lipid-driven disorder of the arterial wall that represents a principal worldwide cause of morbidity and mortality. Coronary heart disease causes 20-22 \% of deaths annually across Europe [1]. Ruptured atherosclerotic plaques account for the majority of myocardial infarctions and ischaemic strokes.

The related condition of abdominal aortic aneurysm (AAA) is a further major cause of mortality, accounting for at least 15,000 deaths per year in the USA [2]. Aneurysms are often asymptomatic until rupture, after which the consequences are frequently fatal. Long-term management requires accurate detection, monitoring of expansion and, in the absence of effective medical therapies, pre-emptive surgical intervention.

Inflammation plays a pivotal role in the pathogenesis of both conditions [3, 4]. In atherosclerosis, macrophage-led inflammation contributes to plaque development and the tendency to rupture [4]. In AAA, chronic inflammation leads to a protease-mediated degradation of the extracellular matrix within the aortic media [5]. This in turn produces structural changes that predispose to dilatation and rupture.

Despite an understanding of the natural history, predicting progression and complications remains challenging. Stress testing and invasive angiography are used to identify sites and severity of stenoses in patients with angina. This information can then guide revascularisation and hence symptom relief. However, the severity of luminal stenosis correlates poorly with the risk of plaque rupture and only $18 \%$ of acute coronary events occur in patients with preexisting stable angina [6].

Ultrasonography and CT are used to detect and characterise AAAs. Although aneurysm size is a dominant 
factor in determining the subsequent expansion rate, it only explains about $60 \%$ of the variability in this and is a poor predictor of aneurysm rupture [7].

Both disorders are diseases of the arterial wall, and in this respect imaging that centres around the vessel lumen will inherently be limited. This account will review noninvasive techniques that track various pathological processes within the arterial wall, focusing specifically on methods of imaging inflammation.

\section{Atherosclerosis and plaque rupture}

Pathophysiology

Atherosclerosis is a multifocal inflammatory disorder, which occurs in response to deposition of low-density lipoproteins in the vessel wall [4]. Expression of adhesion molecules by endothelial cells leads to recruitment of inflammatory cells, including monocytes and T-lymphocytes. Macrophages take up modified lipoproteins via scavenger receptors and differentiate further to become foam cells. A typical atheroma is composed of a soft and unstable lipid-rich cavity, with an overlying fibrous cap composed of smooth muscle cells separating the necrotic core from the arterial lumen [8].

Acute plaque rupture exposes thrombogenic material to the arterial lumen leading to vascular events such as stroke and myocardial infarction [9]. Pathogenic mechanisms underlying plaque rupture include degradation of the fibrous cap by macrophage-derived proteolytic enzymes [10] and intraplaque haemorrhage [11] due to disruption of fragile capillaries from the vasa vasorum, which form in response to hypoxia within the atheroma [12].

The rate of atherosclerotic progression and risk of rupture vary greatly and are difficult to predict. For example, coronary artery lesions may remain asymptomatic for decades and up to $40 \%$ of the coronary wall may be involved before significant luminal narrowing occurs [13]. Coronary lesions producing stable angina are mature fibrocalcific plaques with $>50-70 \%$ luminal stenosis, which represent a different phenotype to the less stable ruptureprone plaques that lead to acute coronary events [14]. While most acute events are caused by immature lesions demonstrating $<50 \%$ luminal stenosis, the presence of severe obstructive coronary artery disease may serve as a marker for rupture-prone plaques elsewhere [14].

The thin-cap fibroatheroma (TCFA) is considered the classical rupture-prone lesion [4]. A TCFA consists of a large necrotic core, within a thin fibrous cap with a high density of macrophages and reduction in vascular smooth muscle cells [10]. These and other high-risk features (e.g. 'spotty calcification' and intra-plaque vasa vasorum) can be visualised non-invasively using MR or CT. For imaging arterial wall inflammation, there has been significant progress in the development and validation of nuclear and molecular techniques.

\section{Imaging inflammation in atherosclerotic plaques}

Nuclear and molecular imaging

To complement conventional anatomical vascular imaging techniques, nuclear and molecular methods aim to detect and quantify processes implicated in plaque rupture, such as inflammation, calcification, neovascularization and apoptosis. Nuclear imaging enables new ways of identifying high-risk plaques, contributes to our understanding of pathophysiology in vivo and can be used to evaluate new therapeutic agents [15].

The principal advantage of nuclear imaging is the high sensitivity with which tracers can be detected at the site of interest compared with other methods such as MR or CT. Positron-emission tomography (PET) and single-photon emission CT can detect picomolar concentrations of radionuclide. Due to limited spatial resolution, the resultant images need to be co-registered with CT or MR images to allow accurate anatomical localisation of tracer uptake. The most widely validated PET tracer in vascular imaging is ${ }^{18} \mathrm{~F}$ fluorodeoxyglucose (FDG). More recently, other tracers have emerged, often with existing applications in oncology.

\section{Imaging inflammation using FDG PET}

Fluorodeoxyglucose is a glucose analogue that is taken up by cells during glucose metabolism. Upon entry to the cell, FDG is phosphorylated and becomes trapped within the cell. FDG, therefore, accumulates in proportion to metabolic activity. FDG uptake can be quantified using standardised uptake value and target-to-background ratio. Arterial FDG PET generally requires longer circulation times ( $>90 \mathrm{~min}$ ) than when the technique is used for oncological imaging to allow adequate blood clearance and, therefore, a favourable arterial wall signal.

Arterial FDG uptake was first recognised in studies of patients undergoing PET cancer staging [16]. FDG uptake is thought to reflect inflammation within the arterial wall, because activated macrophages have higher metabolic activity than other cellular elements of plaques or of the healthy arterial wall [17]. More recently, in vitro studies have demonstrated that FDG uptake increases as macrophages undergo differentiation to foam cells [18].

Studies using a rabbit model of atherosclerosis reveal that FDG uptake correlates closely with macrophage 
content assessed histologically ( $r=0.93, p<0.002)$ [19]. In rabbit models of progressive atherosclerosis, after balloon aortic injury and high-fat diet, FDG uptake has been shown to be higher in diseased regions as compared with healthy arterial wall and can be reduced with reversion to a normal diet [20]. Additionally, after pharmacological triggering of thrombosis, FDG PET is able to differentiate thrombosis-prone plaques with reasonable accuracy [21].

Whilst murine models are widely used in the study of atherosclerosis, the use of FDG PET in mice has proved challenging due to their small size and the limited spatial resolution of PET [22]. One study circumvented this issue by administering non-radioactive FDG and then using mass spectrometry to detect metabolites of FDG-6-phosphate within the plaque [23]. This approach demonstrated significant accumulation within inflamed plaque compared with control vessels, as a proof of principle experiment.

Despite these difficulties, there have been studies demonstrating increased ${ }^{18} \mathrm{~F}$-FDG uptake using PET in mice. $\mathrm{ApoE}^{-/-}$mice fed a high-fat diet demonstrated increased aortic ${ }^{18}$ F-FDG PET signal compared with mice fed a control diet, with this difference increasing with age [24]. Strength of FDG signal also correlated with gene expression of markers of pathological processes central to atherosclerosis [24], including CD68, lectin-like oxidised lowdensity lipoprotein (LDL) receptor-1 and hypoxia inducible factor- $1 \alpha$.

In a prospective vascular imaging study with FDG PET, Rudd and colleagues [25] showed that FDG accumulation rate was $27 \%$ greater in the culprit carotid artery after a recent stroke or transient ischaemic attack (TIA) than in contralateral asymptomatic lesions. As in animal models, carotid arterial FDG uptake has been shown to correlate most significantly with the macrophage content of plaques removed at endarterectomy [26], and not with wall thickness, smooth muscle cell content or degree of stenosis Fig. 1.

Uptake of FDG is increased in subjects with cardiovascular risk factors [27] and with elevated biomarkers of inflammation such as C-reactive protein [28]. It has been shown to be reproducible, with low levels of inter-observer and short-term variability [29]. In carotid imaging, high FDG uptake correlates well with features of vulnerability noted on other modalities, for example, echolucency on ultrasound [30] and lipid rich cores on MRI [31]. Vascular FDG PET is being used to investigate the excess cardiovascular risk associated with other chronic inflammatory diseases such as HIV [32], chronic obstructive pulmonary disease [33] and rheumatoid arthritis [34].

Coronary artery imaging with FDG PET is frequently complicated by intense myocardial tracer uptake that can overwhelm the signal from individual plaques. Compensation for cardiac and respiratory motion during acquisition
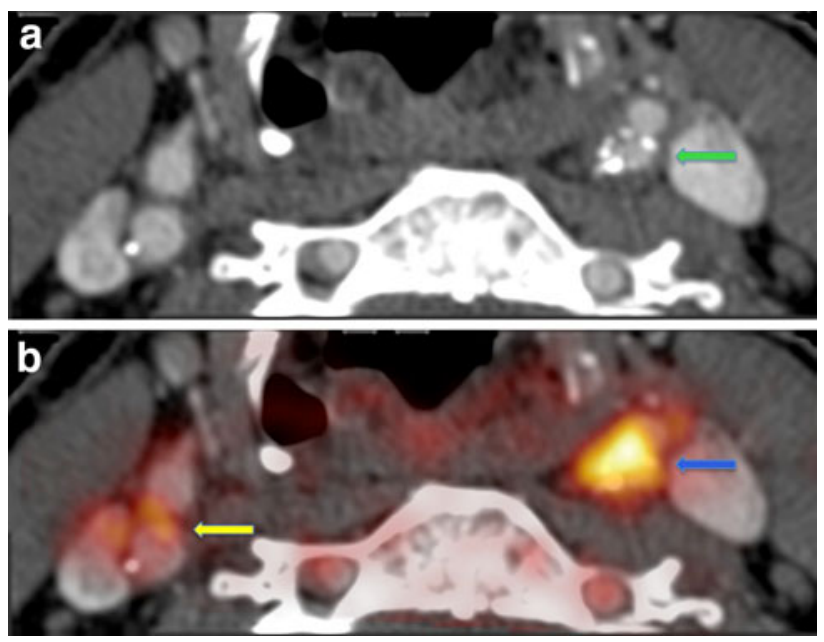

Fig. $1{ }^{18}$ F-FDG PET/CT imaging after recent stroke, a axial CT image showing culprit left ICA lesion (green arrow); b co-registered PET/CT images demonstrating intense FDG uptake in culprit left ICA (blue arrow), note lesser uptake at bifurcation of right carotid (yellow arrow) (colour figure online)

of the PET dataset is possible but adds complexity. Despite this, using dietary manipulation to suppress myocardial glucose usage, Rogers and colleagues [35] have shown that culprit plaques after acute coronary syndrome have higher FDG uptake than lesions causing stable angina, though others have shown that even with such measures, around $50 \%$ of coronary segments will not be analysable [36]. More specific PET tracers will be required for the optimal imaging of coronary plaque inflammation [15].

Serial FDG PET imaging can be used to assess the impact of anti-atherosclerotic therapy. Three months of simvastatin therapy has been shown to produce a reduction in carotid artery FDG uptake, consistent with an antiinflammatory effect of the drug [37]. Mizoguchi and colleagues [38] used FDG to demonstrate a reduction in vascular inflammation with pioglitazone. Similarly, in an investigation of vascular inflammation in rheumatoid arthritis, 8 weeks of anti-TNF $\alpha$ therapy reduced aortic FDG uptake in addition to showing the expected benefits in terms of general disease activity [34].

In retrospective analyses of FDG PET studies undertaken for oncology staging, high levels of baseline vascular FDG uptake were associated with subsequent cardiovascular events in multivariate analysis [39]. Of clinical relevance, a similar analysis in a high-risk stroke population demonstrated that carotid arterial FDG uptake independently predicted recurrent cerebral events [40]. This finding is now being tested in a multi-centre international trial. If successful, arterial PET imaging after stroke and TIA in selected subjects might allow better targeting of endarterectomy.

Although histological, clinical and gene expression evidence supports the hypothesis that arterial FDG uptake 
reflects vascular macrophage accumulation, controversies remain. FDG is a non-specific, non-targeted tracer and overall signal intensity may depend on other glucose-avid processes within the plaque. For example, the core of an atherosclerotic plaque constitutes an area of relative hypoxia and under these circumstances, glucose uptake is increased. Hypoxia leads to upregulation of GLUT-1 transport proteins and increased rates of glycolysis [41]. Furthermore, hypoxia produces neovascularization, which may impact on FDG delivery and signal strength [42]. Nevertheless, both hypoxia and neovascularization are hallmarks of plaque instability, and their non-invasive measurement may still provide important insights.

\section{Novel approaches for imaging inflammation with PET}

Several alternative tracers have their roots in cancer imaging, and await prospective clinical evaluation.

${ }^{11} \mathrm{C}$ and ${ }^{18} \mathrm{~F}$-choline

A choline-specific transporter exists on macrophages. This is upregulated with cellular activation [43] and can be exploited for imaging atherosclerotic plaque inflammation. Studies using radiolabelled choline in $\mathrm{ApoE}^{-1-}$ mice revealed that choline uptake was more sensitive in detecting carotid artery plaques than ${ }^{18}$ F-FDG was [44] and showed significantly higher uptake in atherosclerotic versus normal artery wall [45].

In patients, retrospective analyses of those imaged for prostate cancer staging have confirmed arterial choline uptake [46]. Unlike FDG, choline does not demonstrate high myocardial uptake, but does accumulate in the liver, perhaps precluding assessment of the coronary arteries on the inferior surface of the heart. Definitive studies using this agent in atherosclerosis with histological verification of the image signal are still needed.

\section{${ }^{11} \mathrm{C}-\mathrm{PK} 11195$}

${ }^{11} \mathrm{C}-\mathrm{PK} 11195$ is a ligand for translocator protein (TSPO), heavily expressed by activated macrophages [47]. It has been used in the imaging of neuroinflammation in multiple sclerosis. Several studies have demonstrated a potential role in plaque imaging. ${ }^{11} \mathrm{C}$-PK11195 uptake is higher in symptomatic carotid arteries compared with asymptomatic plaques [48]. Autoradiography confirmed co-localisation with CD68 immunohistochemistry, implying uptake by macrophages.

Despite these results, the short half-life of ${ }^{11} \mathrm{C}$ requires on-site facilities for tracer generation, likely limiting clinical application.

\section{${ }^{68} \mathrm{Ga}$-DOTATATE}

${ }^{68} \mathrm{Ga}$-DOTATATE is a gallium-based tracer, currently used in neuroendocrine tumour imaging. ${ }^{68} \mathrm{Ga}$-DOTATATE binds somatostatin type 2 receptors, also expressed by activated macrophages. In a retrospective study, ${ }^{68} \mathrm{Ga}-$ DOTATATE uptake correlated with the presence of calcified plaques on coronary CT, history of chest pain and previous vascular events [49]. Further studies have demonstrated a correlation with cardiovascular risk factors [50]. ${ }^{68} \mathrm{Ga}$-DOTATATE uptake often did not co-localise with FDG. It has been suggested that ${ }^{68} \mathrm{Ga}$-DOTATATE may be more specific for activated macrophages, though differing tracer kinetics may also explain these findings.

\section{Imaging calcification with ${ }^{18}$ F-sodium fluoride (NaF)}

Microcalcification within plaques is known to increase the risk of rupture, perhaps due to stress-induced microfractures around calcified areas [51]. Although mechanisms of vascular calcification are incompletely understood, it is known to be an active process contributing towards plaque progression [52]. In the initial stages, cytokines secreted by macrophages induce osteogenic transformation of vascular smooth muscle cells. Calcification, therefore, occurs as a response to inflammation. Areas of microcalcification have been shown to evolve close to areas of intense inflammation [53]. Established areas of microcalcification induce further inflammatory reaction from macrophages, therefore actively driving plaque progression [54]. When calcification progresses to such an extent that it is detectable by conventional CT (macrocalcification), the inflammatory component has usually subsided [52].

${ }^{18} \mathrm{~F}-\mathrm{NaF}$ has an established role in imaging areas of new bone formation in the context of cancer metastasis and in detection of osteoblastic tumours. ${ }^{18} \mathrm{~F}$-fluoride ions become bound to exposed hydroxyapatite in exchange for hydroxyl ions. Retrospective studies of patients undergoing oncological NaF PET imaging have revealed that vascular $\mathrm{NaF}$ uptake may identify areas of developing arterial calcification [55]. ${ }^{18} \mathrm{~F}-\mathrm{NaF}$ PET thus holds promise as means of imaging dynamic calcification in inflamed, atherosclerotic plaques [56].

In a subgroup analysis of a population recruited for assessment of calcific aortic stenosis using ${ }^{18} \mathrm{~F}-\mathrm{NaF}$ PET, Dweck and colleagues [36] demonstrated that NaF could be used to report on coronary calcification. Unlike FDG, $\mathrm{NaF}$ displayed no myocardial uptake and discrete areas of activity could be localised to individual plaques. ${ }^{18} \mathrm{~F}-\mathrm{NaF}$ uptake was higher in patients with atherosclerosis (calcium score $>0$ ) compared with those without. ${ }^{18} \mathrm{~F}-\mathrm{NaF}$ uptake progressively increased with increasing atherosclerotic 
burden $\left(r^{2}=0.652\right)$. Patients with atherosclerosis could be divided into those displaying and those not displaying elevated ${ }^{18} \mathrm{~F}-\mathrm{NaF}$ uptake. Patients who displayed increased ${ }^{18} \mathrm{~F}-\mathrm{NaF}$ uptake were more likely to have a higher Framingham risk score, previous cardiovascular events, anginal symptoms and prior revascularisation.

In addition, ${ }^{18} \mathrm{~F}-\mathrm{NaF}$ uptake was seen in coronary segments without visible calcification, implying that ${ }^{18} \mathrm{~F}-\mathrm{NaF}$ allows detection of microcalcification below the resolution of CT imaging [56] Fig. 2.

These promising findings need to be confirmed in prospective studies, preferably comparing stable and unstable presentations. Furthermore, mechanistic considerations regarding ${ }^{18} \mathrm{~F}-\mathrm{NaF}$ deposition within the arterial wall need to be confirmed histologically.
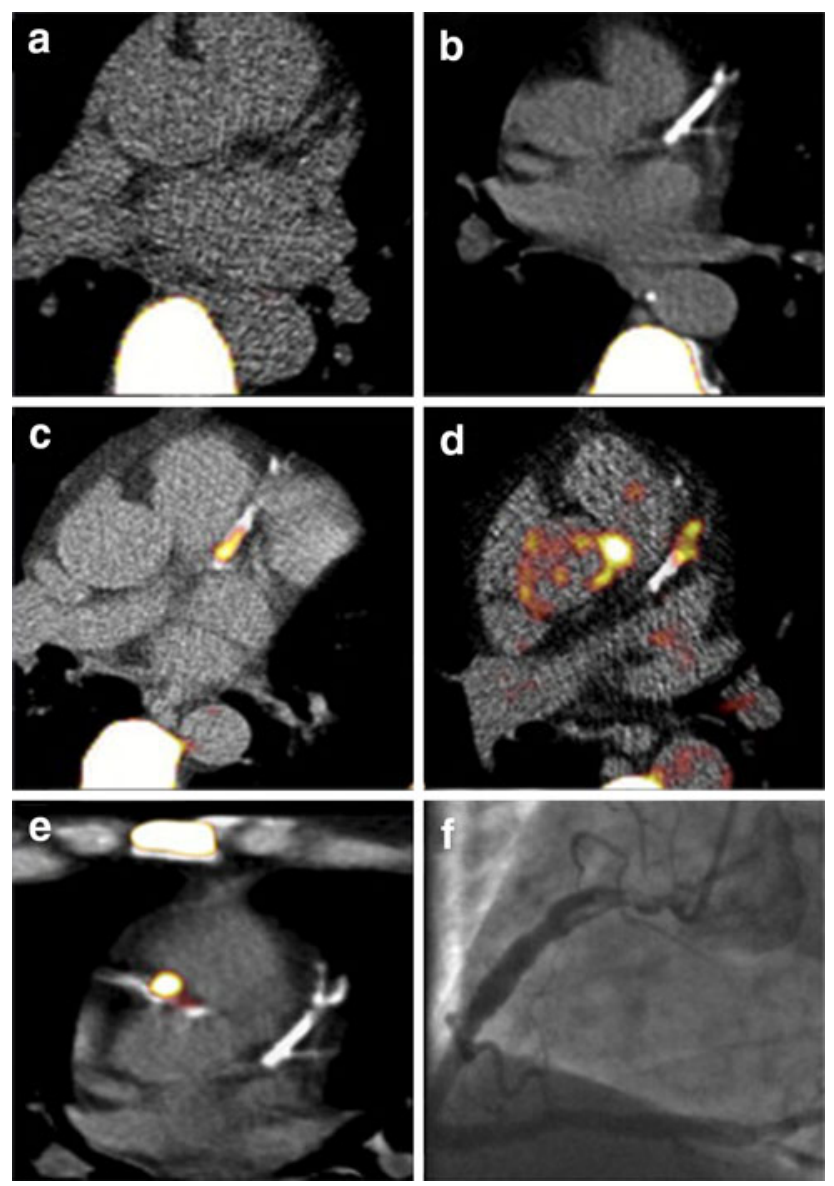

Fig. 2 PET-CT images of ${ }^{18} \mathrm{~F}-\mathrm{NaF}$ activity in coronary arteries. a No coronary calcium and no coronary ${ }^{18} \mathrm{~F}-\mathrm{NaF}$ uptake; b extensive calcification in the left anterior descending artery (LAD) but no ${ }^{18} \mathrm{~F}$ $\mathrm{NaF}$ uptake; $\mathbf{c}$ intense focal ${ }^{18} \mathrm{~F}-\mathrm{NaF}$ uptake in the proximal LAD overlying coronary calcium; $\mathbf{d}$ increased ${ }^{18} \mathrm{~F}-\mathrm{NaF}$ uptake in the midLAD near existing coronary calcification; $e$ intense focal ${ }^{18} \mathrm{~F}-\mathrm{NaF}$ uptake in the proximal right coronary artery (RCA) following recent inferior myocardial infarction; $\mathbf{f}$ RCA confirmed to be the culprit with angiography (reproduced with permission from [36])

\section{Alternative approaches for plaque imaging}

Clinical non-invasive vascular imaging uses CT, ultrasound and MRI and focuses mainly on luminal stenosis. Recent developments mean that these modalities can also be used to report upon the vascular wall.

Although CT does not enable direct assessment of plaque inflammation, it can be used to characterise plaque components, and these can be used to predict acute coronary syndromes [57]. In pre-clinical models, CT can be combined with targeted nanoparticles such as N1177 (iodine-based) and gold high-density lipoprotein to track macrophage accumulation [58]. When used in combination, the signal from these agents can be discriminated using multi-energy $\mathrm{CT}$, providing detailed information about plaque anatomy and cellular accumulation [59]. The relative molecular insensitivity of CT raises concerns about the toxicity of contrast agent doses required for clinical imaging.

Late-phase contrast-enhanced ultrasound using microbubbles can assess inflammation within carotid plaques [60]. Microbubbles are taken up by phagocytic cells and remain acoustically active for around $30 \mathrm{~min}$. This technique has been shown to be capable of distinguishing symptomatic and asymptomatic plaques [61].

Microbubbles can be targeted towards specific pathological processes through conjugation with various ligands. For example, microbubbles can be targeted to vascular cell adhesion molecule-1 (VCAM-1). VCAM-1 is expressed by activated endothelial cells and is involved in the recruitment of leukocytes to sites of inflammation. The feasibility of such targeting has been demonstrated in preclinical studies [62].

Perhaps most promisingly, MRI has been used to characterise vascular inflammation in carotid arteries. Dynamic contrast enhancement of carotid plaque enables evaluation of plaque inflammation and neovascularization [63] and has been validated histologically. Additionally, MRI can be combined with targeted molecular probes to directly assess plaque inflammation. Ultrasmall superparamagnetic iron oxide (USPIO) particles, which have a similar diameter to LDL, accumulate within plaques under conditions of high endothelial permeability [64]. These lead to signal dropout on T2 MRI and can be used to track macrophages and assess changes in the inflammatory status of plaques [65].

Table 1 summarises the role of MRI, CT and ultrasonography in identifying vulnerable plaques.

\section{Abdominal aortic aneurysms}

Pathophysiology

Abdominal aortic aneurysms (AAAs) are defined as focal dilatations of the aorta, where aortic diameter is $>1.5$ times 
Table 1 Role of MRI, CT and ultrasonography in identifying vulnerable plaques

\begin{tabular}{|c|c|c|}
\hline Modality & Newer approaches & Features of plaque vulnerability \\
\hline Ultrasonography & $\begin{array}{l}\text { - Microbubble contrast agents } \\
\text { - Molecular targeting of bubble contrast (e.g. incorporating } \\
\text { VCAM-1 ligand) }\end{array}$ & $\begin{array}{l}\text { - Quantify arterial inflammation [60] and } \\
\text { neovascularization } \\
\text { - Differentiate symptomatic and asymptomatic plaques [61] } \\
\text { - Identify areas of active leukocyte recruitment [62] }\end{array}$ \\
\hline $\begin{array}{l}\text { Computed } \\
\text { tomography }\end{array}$ & $\begin{array}{l}\text { - Multidetector CT (MDCT) } \\
\text { - Nanoparticles, e.g. N1177 (iodine-based), gold-coupled } \\
\text { high-density lipoprotein (Au-HDL) }\end{array}$ & $\begin{array}{l}\text { - MDCT differentiates calcified vs non-calcified plaques } \\
\text { [15] } \\
\text { - MDCT revealed high-risk features, e.g. spotty } \\
\text { calcification, large necrotic core and positive remodelling } \\
\text { [57] } \\
\text { - Nanoparticles can track macrophage accumulation [58, } \\
\text { 59] }\end{array}$ \\
\hline $\begin{array}{l}\text { Magnetic } \\
\text { resonance } \\
\text { imaging }\end{array}$ & $\begin{array}{l}\text { - Gadolinium and dynamic contrast enhancement (DCE) } \\
\text { - Multi-contrast MRI } \\
\text { - Ultrasmall superparamagnetic iron oxide (USPIO) particles }\end{array}$ & $\begin{array}{l}\text { - Visualise necrotic core, fibrous cap, neovascularization, } \\
\text { intraplaque haemorrhage, and calcification [15] } \\
\text { - DCE can evaluate inflammation and neovascularization } \\
\text { [63] } \\
\text { - USPIO particles track macrophage accumulation and } \\
\text { plaque inflammation [65] }\end{array}$ \\
\hline
\end{tabular}

normal, or has an absolute value $>3 \mathrm{~cm}$. Most aneurysms remain asymptomatic until rupture.

Abdominal aortic aneurysms usually form below the level of the renal arteries. The volume of blood flow is lower in the infrarenal aorta, which may lead to reversed flow and consequent oscillatory shear stress, potentially causing aneurysmal dilatation [66]. Most AAAs are fusiform, with a circumferential dilatation involving all layers of the arterial wall. Turbulent flow around the aneurysm leads to deposition of laminated thrombus on the luminal surface of the aneurysm.

Dense cellular infiltration throughout the media and adventitia is a common histological finding in AAAs [67]. Inflammatory cells, including macrophages, neutrophils and lymphocytes enter the aneurysm through the vasa vasorum [68] and by infiltrating through the luminal thrombus and intima. These cells secrete destructive enzymes including matrix metalloproteases (MMPs) and reactive oxygen species, which cause degradation of the extracellular matrix [69], leading to fragmentation and destruction of structural proteins such as elastin, and consequent thinning of the arterial media. In addition, inflammation and hypoxia lead to new vessel formation and loss of vascular smooth muscle cells. These mechanisms increase the risk of AAA rupture.

\section{Imaging abdominal aortic aneurysm progression}

Maximum diameter is currently the most widely accepted method for surveillance of AAAs. A cut-off value of $5.5 \mathrm{~cm}$ is used to determine which patients require surgery. Aneurysms measuring $5.5 \mathrm{~cm}$ or more have an untreated 5-year rupture risk of 40-60\%, with rupture leading to a total mortality of more than $90 \%$ [70]. Factors including patient co-morbidities and operative risk are balanced against risk of rupture when deciding timing of surgery.

Size is not the only determinant of rupture risk, and using vessel dimensions alone means that unexpected rupture of smaller aneurysms may be missed, whilst larger, more stable, aneurysms may be operated on unnecessarily.

The risk of rupture depends on the stresses exerted on the arterial wall and on the intrinsic strength of the arterial wall [71]. The arterial wall is destabilised through chronic inflammation and proteolysis. Using imaging to non-invasively assess the pathological processes occurring within the arterial wall may provide more accurate means of assessing rupture risk.

\section{${ }^{18}$ F-FDG PET in abdominal aortic aneurysm imaging}

In a prospective study of 15 patients undergoing ${ }^{18} \mathrm{~F}-\mathrm{FDG}$ PET/CT and open AAA repair, Reeps and colleagues demonstrated that patients with acutely symptomatic aneurysms had significantly higher ${ }^{18}$ F-FDG uptake compared with asymptomatic individuals. Histological analysis of operative samples confirmed that areas of high FDG uptake also showed higher densities of macrophages, T-lymphocytes and increased expression of MMP enzymes [72] Fig. 3.

These findings have been corroborated by work in animal models. In rats, orthotopic implantation of decellularized guinea pig abdominal aorta leads to pathological changes comparable to AAA. Imaged with FDG PET, implanted rats displayed higher levels of aortic FDG uptake compared with controls. Histological analysis 

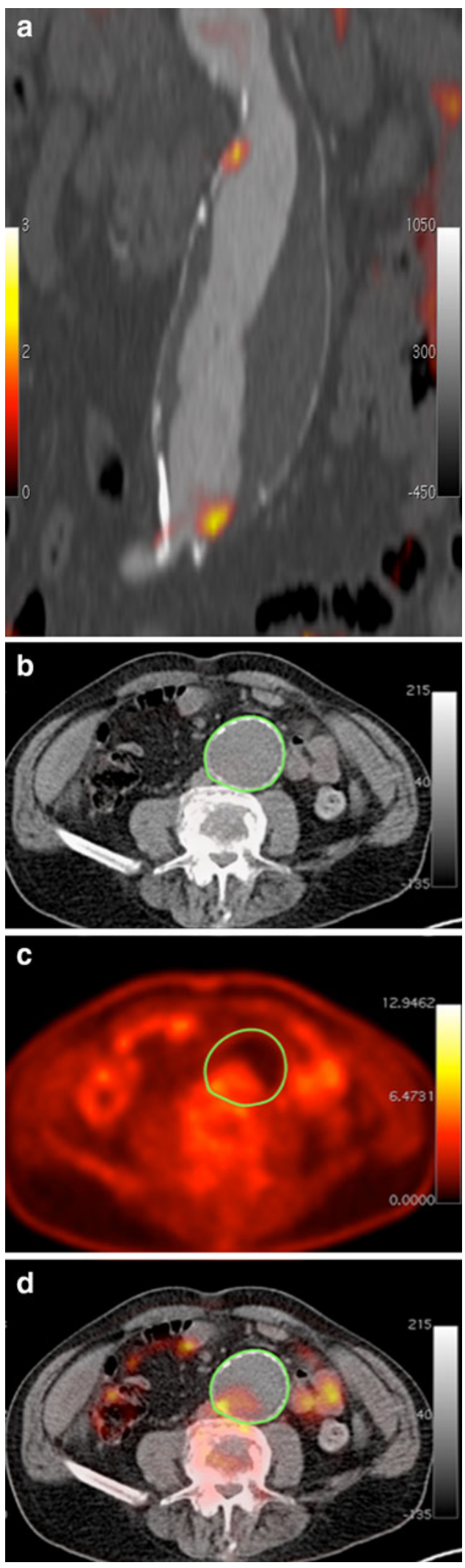

Fig. 3 a Coronal ${ }^{18}$ F-FDG PET/CT image of an AAA showing focal FDG uptake in the aneurysm wall and $\mathbf{b}$ axial CT, $\mathbf{c}{ }^{18}$ F-FDG PET and $\mathbf{d}$ fused PET/CT images of the same AAA confirmed that this correlated closely with the quantity of macrophages and CD8 T-lymphocytes [73].

The role of FDG in AAA surveillance remains controversial, however. In a study of 40 consecutive male patients with asymptomatic AAA, FDG signal in the aneurysmal aorta was not increased compared wtih adjacent nonaneurysmal segments and corresponding regions in control subjects. In fact, FDG signal in the aneurysmal aorta was lower than in controls [74]. Further work suggested that this low uptake may reflect lower cell density in the aneurysmal wall compared with normal regions [75].

Inconsistencies in AAA FDG PET may be due to technical limitations such as the partial volume effect. The AAA wall often measures only 1-2 $\mathrm{mm}$ and is, therefore, smaller than the spatial resolution of many PET scanners. This limitation can lead to loss of signal (partial volume effect). Newer software tools can correct for this and improve accuracy [76].

\section{Other PET tracers}

${ }^{11} \mathrm{~F}$-choline $(\mathrm{FCH})$ and ${ }^{18} \mathrm{~F}$-DPA714 (a TSPO ligand similar to PK11195) have both been used as PET tracers to assess leukocyte activity in AAA animal models. FCH signal is higher in aneurysmal aortic segments compared with controls, with the increase correlating with macrophage density. However, FCH proved to be less sensitive than FDG. There was no significant difference in ${ }^{18} \mathrm{~F}$ DPA714 uptake for AAA compared with controls [73].

\section{Magnetic resonance imaging}

As in atherosclerosis, macrophage activity can be tracked in AAA using USPIO particles. In a study of 29 individuals with asymptomatic AAA, patients with distinct regions of mural USPIO uptake had three-fold higher growth rates than those lacking distinct uptake. Histological analysis confirmed colocalisation with areas of macrophage activity [77].

Macrophage activity within aneurysms can also be imaged with agents specific to MMP enzymes. The agent P947 consists of an MMP inhibitor combined with a gadolinium chelate. In an elastase-induced rat model of AAA, P947 has shown enhanced MMP targeting in AAA compared with a scrambled control agent and un-targeted gadolinium chelate [78].

Near-infrared fluorescence and bioluminescence

These highly sensitive techniques can provide information regarding molecular processes during aneurysm progression. Near-infrared light is used because it penetrates tissues more deeply than visible light. In pre-clinical studies, optical probes sensitive to protease activity have been used 
to track MMP activity in AAAs. MMPSense is activated by MMP enzymes, and in animal models there is a linear relationship between detected proteolytic activity and aneurysmal growth [79].

Bioluminescence imaging relies on cells that have been genetically modified to express luciferase, an enzyme that emits light when exposed to luciferin substrate. When luciferase-expressing macrophages are injected into animals with experimental AAAs, they demonstrate increased aortic bioluminescence compared with controls [80]. The clinical application of this technique, however, will be limited due to poor tissue penetration and the need to inject transgenic cells.

\section{Conclusions}

Recent advances in several imaging modalities indicate that significant information about pathology within the arterial wall can be obtained non-invasively, both in the context of atherosclerosis and aneurysm disease. The results can assist in understanding the underlying disease process in testing the response to new drugs and potentially in improving risk stratification in individual patients.

Future research should yield tracers with better specificity, and further hardware integration (e.g. combined PET/MRI) will allow faster imaging, lower radiation exposure and easier integration into clinical practice.

Acknowledgments JHFR is supported by the Cambridge NIHR Biomedical Research Centre.

Conflict of interest N.K. Rajani, F.R. Joshi, J.M. Tarkin and J.H.F. Rudd declare that they have no conflict of interest.

Human and Animal Studies This article does not contain any studies with human or animal subjects performed by any of the authors.

\section{References}

1. Nichols M, Townsend N, Scarborough P, Rayner M (2013) Cardiovascular disease in Europe: epidemiological update. Eur Heart J. doi:10.1093/eurheartj/eht356

2. Lederle FA, Johnson GR, Wilson SE, Chute EP, Hye RJ, Makaroun MS, Barone GW, Bandyk D, Moneta GL, Makhoul RG (2000) The aneurysm detection and management study screening program: validation cohort and final results. Aneurysm Detection and Management Veterans Affairs Cooperative Study Investigators. Arch Intern Med 160:1425-1430

3. Michel JB (2001) Contrasting outcomes of atheroma evolution: intimal accumulation versus medial destruction. Arterioscler Thromb Vasc Biol 21:1389-1392

4. Libby P (2002) Inflammation in atherosclerosis. Nature 420:868-874

5. Hellenthal FA, Buurman WA, Wodzig WK, Schurink GW (2009) Biomarkers of AAA progression. Part 1: extracellular matrix degeneration. Nat Rev Cardiol 6:464-474
6. Roger VL, Go AS, Lloyd-Jones DM et al (2012) Heart disease and stroke statistics-2012 update: a report from the American Heart Association. Circulation 125:e2-e220

7. Golledge J, Muller J, Daugherty A, Norman P (2006) Abdominal aortic aneurysm: pathogenesis and implications for management. Arterioscler Thromb Vasc Biol 26:2605-2613

8. Stary HC, Chandler AB, Dinsmore RE, Fuster V, Glagov S, Insull W Jr, Rosenfeld ME, Schwartz CJ, Wagner WD, Wissler RW (1995) A definition of advanced types of atherosclerotic lesions and a histological classification of atherosclerosis. A report from the Committee on Vascular Lesions of the Council on Arteriosclerosis American Heart Association. Circulation 92:1355-1374

9. Redgrave JN, Lovett JK, Gallagher PJ, Rothwell PM (2006) Histological assessment of 526 symptomatic carotid plaques in relation to the nature and timing of ischemic symptoms: the Oxford plaque study. Circulation 113:2320-2328

10. Kolodgie FD, Burke AP, Farb A, Gold HK, Yuan J, Narula J, Finn AV, Virmani R (2001) The thin-cap fibroatheroma: a type of vulnerable plaque: the major precursor lesion to acute coronary syndromes. Curr Opin Cardiol 16:285-292

11. Kolodgie FD, Gold HK, Burke AP, Fowler DR, Kruth HS, Weber DK, Farb A, Guerrero LJ, Hayase M, Kutys R, Narula J, Finn AV, Virmani R (2003) Intraplaque hemorrhage and progression of coronary atheroma. N Engl J Med 349:2316-2325

12. Sluimer JC, Daemen MJ (2009) Novel concepts in atherogenesis: angiogenesis and hypoxia in atherosclerosis. J Pathol 218:7-29

13. Fishbein MC, Siegel RJ (1996) How big are coronary atherosclerotic plaques that rupture? Circulation 94:2662-2666

14. Libby P (1995) Molecular bases of the acute coronary syndromes. Circulation 91:2844-2850

15. Joshi FR, Lindsay AC, Obaid DR, Falk E, Rudd JH (2012) Noninvasive imaging of atherosclerosis. Eur Heart $\mathrm{J}$ Cardiovasc Imaging 13:205-218

16. Yun M, Yeh D, Araujo LI, Jang S, Newberg A, Alavi A (2001) F-18 FDG uptake in the large arteries: a new observation. Clin Nucl Med 26:314-319

17. Newsholme P, Curi R, Gordon S, Newsholme EA (1986) Metabolism of glucose, glutamine, long-chain fatty acids and ketone bodies by murine macrophages. Biochem J 239:121-125

18. Ogawa M, Nakamura S, Saito Y, Kosugi M, Magata Y (2012) What can be seen by ${ }^{18} \mathrm{~F}$-FDG PET in atherosclerosis imaging? The effect of foam cell formation on ${ }^{18} \mathrm{~F}-\mathrm{FDG}$ uptake to macrophages in vitro. $\mathrm{J}$ Nucl Med 53:55-58

19. Tawakol A, Migrino RQ, Hoffmann U, Abbara S, Houser S, Gewirtz H, Muller JE, Brady TJ, Fischman AJ (2005) Noninvasive in vivo measurement of vascular inflammation with F-18 Fluorodeoxyglucose positron emission tomography. J Nucl Cardiol 12:294-301

20. Worthley SG, Zhang ZY, Machac J, Helft G, Tang C, Liew GY, Zaman AG, Worthley MI, Fayad ZA, Buchsbaum MS, Fuster V, Badimon JJ (2009) In vivo noninvasive serial monitoring of FDG-PET progression and regression in a rabbit model of atherosclerosis. Int J Cardiovasc Imaging 25:251-257

21. Zhao QM, Zhao X, Feng TT, Zhang MD, Zhuang XC, Zhao XC, Li LQ, Li DP, Liu Y (2013) Detection of vulnerable atherosclerotic plaque and prediction of thrombosis events in a rabbit model using (18)F-FDG -PET/CT. PLoS ONE 8:e61140

22. Laurberg JM, Olsen AK, Hansen SB, Bottcher M, Morrison M, Ricketts SA, Falk E (2007) Imaging of vulnerable atherosclerotic plaques with FDG-micro PET: no FDG accumulation. Atherosclerosis 192:275-282

23. Conway RG, Chernet E, De Rosa DC, Benschop RJ, Need AB, Collins EC, Bean JS, Kalbfleisch JM, Rekhter MD (2012) Glucose metabolic trapping in mouse arteries: nonradioactive assay of atherosclerotic plaque inflammation applicable to drug discovery. PLoS ONE 7:e50349 
24. Hag AM, Pedersen SF, Christoffersen C, Binderup T, Jensen MM, Jørgensen JT, Skovgaard D, Ripa RS, Kjaer A (2012) (18)FFDG PET imaging of murine atherosclerosis: association with gene expression of key molecular markers. PLoS ONE 7:e50908

25. Rudd JH, Warburton EA, Fryer TD, Jones HA, Clark JC, Antoun N, Johnström P, Davenport AP, Kirkpatrick PJ, Arch BN, Pickard JD, Weissberg PL (2002) Imaging atherosclerotic plaque inflammation with $[18 \mathrm{~F}]$-fluorodeoxyglucose positron emission tomography. Circulation 105:2708-2711

26. Tawakol A, Migrino RQ, Bashian GG, Bedri S, Vermylen D, Cury RC, Yates D, LaMuraglia GM, Furie K, Houser S, Gewirtz H, Muller JE, Brady TJ, Fischman AJ (2006) In vivo ${ }^{18}$ F-fluorodeoxyglucose positron emission tomography imaging provides a non-invasive measure of carotid plaque inflammation in patients. J Am Coll Cardiol 48:1818-1824

27. Rudd JH, Myers KS, Bansilal S, Machac J, Woodward M, Fuster V, Farkouh ME, Fayad ZA (2009) Relationships among regional arterial inflammation, calcification, risk factors, and biomarkers: a prospective fluorodeoxyglucose positron-emission tomography/ computed tomography imaging study. Circ Cardiovasc Imaging 2:107-115

28. Yoo HJ, Kim S, Park MS, Yang SJ, Kim TN, Seo JA, Kim SG, Kim NH, Seo HS, Baik SH, Choi DS, Choi KM (2011) Vascular inflammation stratified by C-reactive protein and low-density lipoprotein cholesterol levels: analysis with ${ }^{18}$ F-FDG PET. J Nucl Med 52:10-17

29. Rudd JH, Myers KS, Bansilal S, Machac J, Rafique A, Farkouh M, Fuster V, Fayad ZA (2007) (18)Fluorodeoxyglucose positron emission tomography imaging of atherosclerotic plaque inflammation is highly reproducible: implications for atherosclerosis therapy trials. J Am Coll Cardiol 50:892-896

30. Graebe M, Pedersen SF, Hojgaard L, Kjaer A, Sillesen H (2010) 18FDG PET and ultrasound echolucency in carotid artery plaques. JACC Cardiovasc Imaging 3:289-295

31. Silvera SS, Aidi HE, Rudd JH, Mani V, Yang L, Farkouh M, Fuster V, Fayad ZA (2009) Multimodality imaging of atherosclerotic plaque activity and composition using FDG-PET/CT and MRI in carotid and femoral arteries. Atherosclerosis 207:139-143

32. Subramanian S, Tawakol A, Burdo TH, Abbara S, Wei J, Vijayakumar J, Corsini E, Abdelbaky A, Zanni MV, Hoffmann U, Williams KC, Lo J, Grinspoon SK (2012) Arterial inflammation in patients with HIV. JAMA 308:379-386

33. Coulson JM, Rudd JH, Duckers JM, Rees JI, Shale DJ, Bolton CE, Cockcroft JR (2010) Excessive aortic inflammation in chronic obstructive pulmonary disease: an 18F-FDG PET pilot study. J Nucl Med 51:1357-1360

34. Mäki-Petäjä KM, Elkhawad M, Cheriyan J, Joshi FR, Ostör AJ, Hall FC, Rudd JH, Wilkinson IB (2012) Anti-tumor necrosis factor- $\alpha$ therapy reduces aortic inflammation and stiffness in patients with rheumatoid arthritis. Circulation 126:2473-2480

35. Rogers IS, Nasir K, Figueroa AL, Cury RC, Hoffmann U, Vermylen DA, Brady TJ, Tawakol A (2010) Feasibility of FDG imaging of the coronary arteries: comparison between acute coronary syndrome and stable angina. JACC Cardiovasc Imaging 3:388-397

36. Dweck MR, Chow MW, Joshi NV, Williams MC, Jones C, Fletcher AM, Richardson H, White A, McKillop G, van Beek EJ, Boon NA, Rudd JH, Newby DE (2012) Coronary arterial ${ }^{18} \mathrm{~F}$ sodium fluoride uptake: a novel marker of plaque biology. J Am Coll Cardiol 59:1539-1548

37. Tahara N, Kai H, Ishibashi M, Nakaura H, Kaida H, Baba K, Hayabuchi N, Imaizumi T (2006) Simvastatin attenuates plaque inflammation: evaluation by fluorodeoxyglucose positron emission tomography. J Am Coll Cardiol 48:1825-1831

38. Mizoguchi M, Tahara N, Tahara A, Nitta Y, Kodama N, Oba T, Mawatari K, Yasukawa H, Kaida H, Ishibashi M, Hayabuchi N,
Harada H, Ikeda H, Yamagishi S, Imaizumi T (2011) Pioglitazone attenuates atherosclerotic plaque inflammation in patients with impaired glucose tolerance or diabetes a prospective, randomized, comparator-controlled study using serial FDG PET/CT imaging study of carotid artery and ascending aorta. JACC Cardiovasc Imaging 4:1110-1118

39. Rominger A, Saam T, Wolpers S, Cyran CC, Schmidt M, Foerster S, Nikolaou K, Reiser MF, Bartenstein P, Hacker M (2009) ${ }^{18}$ F-FDG PET/CT identifies patients at risk for future vascular events in an otherwise asymptomatic cohort with neoplastic disease. J Nucl Med 50:1611-1620

40. Marnane M, Merwick A, Sheehan OC, Hannon N, Foran P, Grant T, Dolan E, Moroney J, Murphy S, O'Rourke K, O'Malley K, O’Donohoe M, McDonnell C, Noone I, Barry M, Crowe M, Kavanagh E, O'Connell M, Kelly PJ (2012) Carotid plaque inflammation on ${ }^{18} \mathrm{~F}$-fluorodeoxyglucose positron emission tomography predicts early stroke recurrence. Ann Neurol 71:709-718

41. Folco EJ, Sheikine Y, Rocha VZ, Christen T, Shvartz E, Sukhova GK, Di Carli MF, Libby P (2011) Hypoxia but not inflammation augments glucose uptake in human macrophages: implications for imaging atherosclerosis with ${ }^{18}$ Fluorine-labeled 2-deoxy-D-glucose positron emission tomography. J Am Coll Cardiol 58:603-614

42. Libby P, Folco E (2011) Tension in the plaque: hypoxia modulates metabolism in atheroma. Circ Res 109:1100-1102

43. Boggs KP, Rock CO, Jackowski S (1995) Lysophosphatidylcholine and 1-O-octadecyl-2-O-methyl-rac-glycero-3-phosphocholine inhibit the CDP-choline pathway of phosphatidylcholine synthesis at the CTP: phosphocholine cytidylyltransferase step. J Biol Chem 270:7757-7764

44. Matter CM, Wyss MT, Meier P, Späth N, von Lukowicz T, Lohmann C, Weber B, Ramirez de Molina A, Lacal JC, Ametamey SM, von Schulthess GK, Lüscher TF, Kaufmann PA, Buck A (2006) ${ }^{18} \mathrm{~F}$-choline images murine atherosclerotic plaques ex vivo. Arterioscler Thromb Vasc Biol 26:584-589

45. Laitinen IE, Luoto P, Någren K, Marjamäki PM, Silvola JM, Hellberg S, Laine VJ, Ylä-Herttuala S, Knuuti J, Roivainen A (2010) Uptake of ${ }^{11} \mathrm{C}$-choline in mouse atherosclerotic plaques. J Nucl Med 51:798-802

46. Kato K, Schober O, Ikeda M, Schäfers M, Ishigaki T, Kies P, Naganawa S, Stegger L (2009) Evaluation and comparison of ${ }^{11} \mathrm{C}$-choline uptake and calcification in aortic and common carotid arterial walls with combined PET/CT. Eur J Nucl Med Mol Imaging 36:1622-1628

47. Bird JL, Izquierdo-Garcia D, Davies JR, Rudd JH, Probst KC, Figg N, Clark JC, Weissberg PL, Davenport AP, Warburton EA (2010) Evaluation of translocator protein quantification as a tool for characterising macrophage burden in human carotid atherosclerosis. Atherosclerosis 210:388-391

48. Gaemperli O, Shalhoub J, Owen DRJ, Lamare F, Johansson S, Fouladi N, Davies AH, Rimoldi OE, Camici PG (2012) Imaging intraplaque inflammation in carotid atherosclerosis with ${ }^{11} \mathrm{C}$ PK11195 positron emission tomography/computed tomography. Eur Heart J 33:1902-1910

49. Rominger A, Saam T, Vogl E (2010) In vivo imaging of macrophage activity in the coronary arteries using ${ }^{68} \mathrm{Ga}$-DOTATATE PET/CT: correlation with coronary calcium burden and risk factors. J Nucl Med 51:193-197

50. Li X, Samnick S, Lapa C, Israel I, Buck AK, Kreissl MC, Bauer W (2012) ${ }^{68} \mathrm{Ga}$-DOTATATE PET/CT for the detection of inflammation of large arteries: correlation with ${ }^{18} \mathrm{~F}$-FDG, calcium burden and risk factors. EJNMMI Res 2:52

51. Huang H, Virmani R, Younis H, Burke AP, Kamm RD, Lee RT (2001) The impact of calcification on the biomechanical stability of atherosclerotic plaques. Circulation 103:1051-1056

52. Chen W, Dilsizian V (2013) Targeted PET/CT imaging of vulnerable atherosclerotic plaques: microcalcification with sodium 
fluoride and inflammation with fluorodeoxyglucose. Curr Cardiol Rep 15:364

53. El-Abbadi M, Giachelli CM (2007) Mechanisms of vascular calcification. Adv Chronic Kidney Dis 14:54-66

54. Nadra I, Mason JC, Philippidis P, Florey O, Smythe CD, McCarthy GM, Landis RC, Haskard DO (2005) Proinflammatory activation of macrophages by basic calcium phosphate crystals via protein kinase $\mathrm{C}$ and MAP kinase pathways: a vicious cycle of inflammation and arterial calcification? Circ Res 96:1248-1256

55. Derlin T, Wisotzki C, Richter U, Apostolova I, Bannas P, Weber C, Mester J, Klutmann S (2011) In vivo imaging of mineral deposition in carotid plaque using ${ }^{18} \mathrm{~F}$-sodium fluoride PET/CT: correlation with atherogenic risk factors. J Nucl Med 52:362-368

56. Dweck MR, Joshi FR, Newby DE, Rudd JH (2012) Noninvasive imaging in cardiovascular therapy: the promise of coronary arterial ${ }^{18} \mathrm{~F}$-sodium fluoride uptake as a marker of plaque biology. Expert Rev Cardiovasc Ther 10:1075-1077

57. Motoyama S, Sarai M, Harigaya $H$, Anno H, Inoue K, Hara T, Naruse H, Ishii J, Hishida H, Wong ND, Virmani R, Kondo T, Ozaki Y, Narula J (2009) Computed tomographic angiography characteristics of atherosclerotic plaques subsequently resulting in acute coronary syndrome. J Am Coll Cardiol 54:49-57

58. Hyafil F, Cornily JC, Feig JE, Gordon R, Vucic E, Amirbekian V, Fisher EA, Fuster V, Feldman LJ, Fayad ZA (2007) Noninvasive detection of macrophages using a nanoparticulate contrast agent for computed tomography. Nat Med 13:636-641

59. Cormode DP, Roessl E, Thran A, Skajaa T, Gordon RE, Schlomka JP, Fuster V, Fisher EA, Mulder WJ, Proksa R, Fayad ZA (2010) Atherosclerotic plaque composition: analysis with multicolor CT and targeted gold nanoparticles. Radiology 256:774-782

60. Owen DR, Shalhoub J, Miller S, Gauthier T, Doryforou O, Davies AH, Leen EL (2010) Inflammation within carotid atherosclerotic plaque: assessment with late-phase contrastenhanced US. Radiology 255:638-644

61. Hoogi A, Adam D, Hoffman A, Kerner H, Reisner S, Gaitini D (2011) Carotid plaque vulnerability: quantification of neovascularization on contrast-enhanced ultrasound with histopathologic correlation. Am J Roentgenol 196:431-436

62. Kaufmann BA, Sanders JM, Davis C, Xie A, Aldred P, Sarembock IJ, Lindner JR (2007) Molecular imaging of inflammation in atherosclerosis with targeted ultrasound detection of vascular cell adhesion molecule-1. Circulation 116:276-284

63. Kerwin W, Hooker A, Spilker M, Vicini P, Ferguson M, Hatsukami T, Yaun C (2003) Quantitative magnetic resonance imaging analysis of neovasculature volume in carotid atherosclerotic plaque. Circulation 107:851-856

64. Ruehm SG, Corot C, Vogt P, Cristina H, Debatin JF (2002) Ultrasmall superparamagnetic iron oxide-enhanced MR imaging of atherosclerotic plaque in hyperlipidemic rabbits. Acad Radiol 9(Suppl 1):S143-S144

65. Tang TY, Howarth SP, Miller SR, Graves MJ, Patterson AJ, U-King-Im JM, Li ZY, Walsh SR, Brown AP, Kirkpatrick PJ, Warburton EA, Hayes PD, Varty K, Boyle JR, Gaunt ME, Zalewski A, Gillard JH (2009) The ATHEROMA (atorvastatin therapy: effects on reduction of macrophage activity) Study. Evaluation using ultrasmall superparamagnetic iron oxideenhanced magnetic resonance imaging in carotid disease. J Am Coll Cardiol 53:2039-2050

66. Amirbekian S, Long RC, Consolini MA, Suo J, Willett NJ, Fielden SW, Giddens DP, Taylor WR, Oshinski JN (2009) In vivo assessment of blood flow patterns in abdominal aorta of mice with MRI: implications for AAA localization. Am J Physiol Heart Circ Physiol 297:H1290-H1295

67. Shimizu K, Mitchell R, Libby P (2006) Inflammation and cellular immune responses in abdominal aortic aneurysms. Arterioscler Thromb Vasc Biol 26:987-994
68. Herron GS, Unemori E, Wong M, Rapp JH, Hibbs MH, Stoney RJ (1991) Connective tissue proteinases and inhibitors in abdominal aortic aneurysms. Involvement of the vasa vasorum in the pathogenesis of aortic aneurysms. Arterioscler Thromb 11:1667-1677

69. Thompson RW, Parks WC (1996) Role of matrix metalloproteinases in abdominal aortic aneurysms. Ann N Y Acad Sci 800:157-174

70. Patel MI, Hardmann DT, Fisher CM, Appleberg M (1995) Current views on the pathogenesis of abdominal aortic aneurysms. J Am Coll Surg 181:371-382

71. Hope TA, Hope MD (2011) Improved risk assessment for abdominal aortic aneurysm rupture: off-the-wall imaging. J Am Coll Cardiol 58:2531-2532

72. Reeps C, Essler M, Pelisek J, Seidl S, Eckstein HH, Krause BJ (2008) Increased ${ }^{18} \mathrm{~F}$-fluorodeoxyglucose uptake in abdominal aortic aneurysms in positron emission/computed tomography is associated with inflammation, aortic wall instability, and acute symptoms. J Vasc Surg 48:417-423

73. Sarda-Mantel L, Alsac JM, Boisgard R, Hervatin F, Montravers F, Tavitian B, Michel JB, Le Guludec D (2012) Comparison of ${ }^{18}$ F-fluoro-deoxy-glucose, ${ }^{18} \mathrm{~F}$-fluoro-methyl-choline, and ${ }^{18} \mathrm{~F}$ DPA714 for positron-emission tomography imaging of leukocyte accumulation in the aortic wall of experimental abdominal aneurysms. J Vasc Surg 56:765-773. doi:10.1016/j.jvs.2012.01. 069

74. Palombo D, Morbelli S, Spinella G, Pane B, Marini C, Rousas N, Massollo M, Cittadini G, Camellino D, Sambuceti G (2012) A positron emission tomography/computed tomography (PET/CT) evaluation of asymptomatic abdominal aortic aneurysms: another point of view. Ann Vasc Surg 26:491-499

75. Marini C, Morbelli S, Armonino R, Spinella G, Riondato M, Massollo M, Sarocchi F, Pane B, Augeri C, Abete L, Ghigliotti G, Palmieri D, Fiz F, Cittadini G, Fulcheri E, Palombo D, Sambuceti G (2012) Direct relationship between cell density and FDG uptake in asymptomatic aortic aneurysm close to surgical threshold: an in vivo and in vitro study. Eur J Nucl Med Mol Imaging 39:91-101

76. Reeps C, Bundschuh RA, Pellisek J, Herz M, van Marwick S, Schwaiger M, Eckstein HH, Nekolla SG, Essler M (2013) Quantitative assessment of glucose metabolism in the vessel wall of abdominal aortic aneurysms: correlation with histology and role of partial volume correction. Int $\mathrm{J}$ Cardiovasc Imaging 29:505-512

77. Richards JM, Semple SI, MacGillivray TJ, Gray C, Langrish JP, Williams M, Dweck M, Wallace W, McKillop G, Chalmers RT, Garden OJ, Newby DE (2011) Abdominal aortic aneurysm growth predicted by uptake of ultrasmall superparamagnetic particles of iron oxide: a pilot study. Circ Cardiovasc Imaging 4:274-281

78. Bazeli R, Coutard M, Duport BD, Lancelot E, Corot C, Laissy JP, Letourneur D, Michel JB, Serfaty JM (2010) In vivo evaluation of a new magnetic resonance imaging contrast agent (P947) to target matrix metalloproteinases in expanding experimental abdominal aortic aneurysms. Invest Radiol 45:662-668

79. Sheth RA, Maricevich M, Mahmood U (2010) In vivo optical molecular imaging of matrix metalloproteinase activity in abdominal aortic aneurysms correlates with treatment effects on growth rate. Atherosclerosis 212:181-187

80. Miyama N, Dua MM, Schultz GM, Kosuge H, Terashima M, Pisani LJ, Dalman RL, McConnell MV (2012) Bioluminescence and magnetic resonance imaging of macrophage homing to experimental abdominal aortic aneurysms. Mol Imaging $11: 126-134$ 